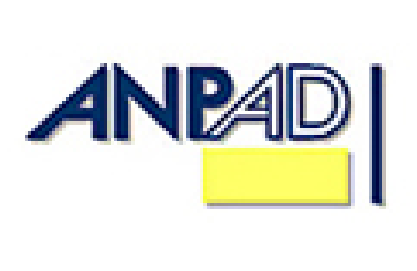

Disponível em

http://www.anpad.org.br/rac

RAC, Rio de Janeiro, v. 18, n. 2, art. 4, pp. 176-195, Mar./Abr. 2014

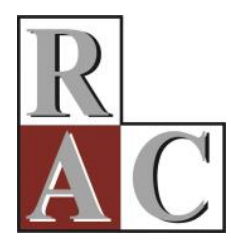

\title{
Um Ensaio Teórico sobre Placement Televisivo e seus Efeitos sobre o Consumidor
}

\section{A Theoretical Essay on TV Show Placement and Its Effects on Consumers}

Martin de La Martinière Petroll

E-mail: martin_petroll@yahoo.com.br Universidade Federal de Santa Catarina - UFSC CAD/UFSC, Campus Universitário Professor João David Ferreira Lima, 88040-900, Florianópolis, SC, Brasil.

Paulo Henrique Müller Prado E-mail: pprado@ufpr.br Universidade Federal do Paraná - UFPR UFPR, R. Prof. Lothário Meissner, 632, sala SA.02N.17, Jardim Botânico, 80210-170, Curitiba, PR, Brasil. 


\title{
Resumo
}

Atualmente, inovações tecnológicas, como os Digital Video Recorders, têm aumentado o poder do consumidor sobre sua exposição aos comerciais exibidos na programação televisiva. Sendo assim, os anunciantes agora inserem seus produtos e marcas nos próprios shows televisivos, o chamado placement, não permitindo, portanto, que o consumidor evite a exposição às mensagens persuasivas exibidas na TV. Tal vantagem faz com que investimentos em placement aumentem exponencialmente em todo o mundo e, com isso, estudos acadêmicos também proliferam, principalmente ao se abordar as dimensões do placement e seus efeitos sobre o comportamento do consumidor. Todavia, estudos sobre os pop-up ads - um novo tipo de placement em formato de banner - são ainda escassos, apesar de também serem cada vez mais utilizados pela mídia televisiva. É nesse sentido, portanto, que se insere o presente artigo, um ensaio teórico sobre os potenciais efeitos das dimensões da proeminência e da congruência do placement do tipo pop-up sobre o processamento de informação realizado pelo consumidor, desde a atenção do telespectador, passando pela memória e atitudes até o seu comportamento de compra. Finaliza-se o estudo com a apresentação do modelo teórico e de sugestões para futuras pesquisas.

Palavras-chave: placement; pop-up ads; proeminência; congruência; transferência de afeto.

\begin{abstract}
Nowadays, technological innovations, such as Digital Video Recorders, have increased consumers' power over their exposure to commercials shown on television. Thus advertisers now insert their own products and brands directly into television shows, called placement. This advantage has exponentially increased worldwide investments in placement, as well as proliferated academic studies about the subject, especially on placement dimensions and its effects on consumer behavior. But studies of pop-up ads - a new type of placement delivered in a banner format - are still scarce, despite their increasing use by television media. Therefore, this article is a theoretical essay about the potential effects of pop-up ads on consumer behavior, from the viewer's attention to advertising, through memory and attitudes, ending in the viewer's buying behavior. Finally, this study presents a theoretical model and suggestions for future research.
\end{abstract}

Key words: placement; pop-up ads; prominence; congruence; affection transfer. 


\section{Introdução}

Os consumidores estão expostos diariamente a inúmeras propagandas veiculadas em televisão, jornais, revistas, outdoors, na Internet, bem como a mensagens visuais implícitas em forma de embalagens de produtos, em uniformes, camisetas, CDs, etc. (Wedel \& Pieters, 2008). Basta folhear, por exemplo, qualquer revista ou jornal para encontrar que cerca de $50 \%$ do seu conteúdo são anúncios de diversas marcas disputando a atenção do consumidor (Pieters \& Wedel, 2004).

Devido a esse bombardeio de propagandas, o consumidor é impedido de absorver todas as marcas anunciadas (Pieters \& Wedel, 2004), pois a sua atenção é escassa (Davenport \& Beck, 2001).

Essa dificuldade em atrair a atenção do consumidor deve ser vista como uma forma de erosão do poder do marketing (Sacharin, 2001), já que reduz a efetividade da propaganda no consumidor, ocasionando prejuízos financeiros para a empresa detentora da marca e, consequentemente, o descumprimento das suas metas de marketing (Pieters \& Wedel, 2004).

Para piorar, inovações tecnológicas têm aumentado o controle do consumidor sobre a exposição da propaganda na programação televisiva, já que ele agora pode sair (fazer zapping) de um comercial de TV, acelerá-lo (fazer zipping) ou pular todos os comerciais (fazer skipping) graças aos chamados Digital Video Recorders (DVR) (Elpers, Wedel, \& Pieters, 2003).

Em contrapartida, empresas investiram mais de US\$ 6 bilhões em 2009 e a previsão é de que dobrem os investimentos até 2016 (PQ Media, n.d.) em propagandas inseridas em programas televisivos, por terem justamente a vantagem de o consumidor não poder evitar a exposição a elas (Cowley \& Barron, 2008). Ou seja, a propaganda está presente no momento em que é exibido o programa televisivo, ao contrário dos comerciais, os quais são veiculados nos intervalos desses programas. Portanto, os consumidores são incapazes de fazer zapping, zipping ou skipping sem perder alguma parte do programa de TV ao qual estão assistindo.

A isso se chama de placement, erroneamente conhecido no Brasil como merchandising ${ }^{(1)}$, já que, segundo literatura sobre o assunto, merchandising trata somente de promoções de produtos e serviços no ponto de venda (Shimp, 2002). Já placement nada mais é do que a inserção paga de produtos com marcas ou identificadores de marca através do uso de meios visuais e/ou sonoros em programação de mídia de massa (Karrh, 1998).

O crescente uso do placement pelo mundo gerencial fez surgir consideráveis pesquisas acadêmicas, de cujos achados podem ser encontrados, por exemplo, em levantamentos feitos por Balasubramanian, Karrh e Patwardhan (2006), Reijmersdal, Neijens e Smit (2009), e Kureshi e Sood (2010). Esses pesquisadores, e outros, de maneira geral, afirmam que os estudos anteriores utilizaram a proeminência, que nada mais é do que características do placement destinadas a torná-lo o foco central da atenção da audiência, e descobriram que um aumento nesta proeminência tem um efeito positivo na memorização da marca pelo consumidor, mas que esse efeito positivo na memória do consumidor não garante, necessariamente, um efeito positivo nas respostas afetivas, pois pode fazer com que o consumidor questione os motivos da marca ter sido inserida no programa televisivo, resultando em atitudes negativas frente à marca veiculada em tal programa (Friestad \& Wright, 1994).

Outra característica inerente a um placement é a congruência entre uma propaganda e o programa televisivo conforme a similaridade entre ambos (Zanjani, Diamond, \& Chan, 2011) e, assim como aconteceu com a proeminência, os resultados encontrados sobre os efeitos da congruência sobre o consumidor também são conflitantes. Ou seja, quanto menos congruente for o placement e seu contexto televisivo, maior será a memorização da marca pelo consumidor por destoar a marca do programa televisivo, mas maiores serão as razões para o consumidor indagar sobre os motivos da sua presença naquele show de TV, resultando em atitudes negativas frente à marca veiculada no programa televisivo (Friestad \& Wright, 1994). Já outros estudos verificaram a congruência afetiva entre propaganda e programa televisivo. Por exemplo, programas televisivos positivos (negativos) 
afetivamente geram atitudes mais favoráveis (desfavoráveis) à propaganda e aos produtos e marcas anunciadas (Martin, 2003).

Todavia, é intrigante como não há estudos sobre os efeitos de um tipo de placement atualmente muito utilizado no mundo televisivo: os pop-up ads. Considerados os novos invasores da televisão pela NYDailyNews já em 2007, os pop-up ads são propagandas em estilo de banner e que estão sobrepostos ao programa televisivo. Devido a isso, normalmente eles são colocados na periferia da tela, frequentemente no limiar de baixo ou de cima da mesma.

Sendo assim, acredita-se que os pop-up ads possam afetar o consumidor, e que suas características sejam similares ao placement tradicional, como a proeminência e a congruência. Além disso, entende-se que possa haver uma transferência de afeto entre os pop-up ads e os programas televisivos, já que os primeiros estão presentes no mesmo momento em que o programa de TV está sendo exibido. Todavia, indaga-se, assim como fizeram Brasel e Gips (2008), qual a direção dessa transferência, se do programa televisivo para o pop-up ad ou inversa.

Finalmente, e principalmente pelo fato de ainda não haver estudos sobre pop-up ads e seus efeitos sobre o consumidor, bem como não haver estudos sobre a transferência inversa de afeto é que se insere este estudo teórico que tenta suscitar os possíveis efeitos desse novo tipo de placement para, em pesquisas posteriores, ratificar ou retificar as sugestões aqui mencionadas sobre a importância do estudo dos pop-up ads à Academia.

\section{Referencial Teórico}

O placement não é novo. Segundo Newell, Salmon e Chang (2006), ele surgiu no fim do século XIX, em filmes como os dos irmãos Lumière, sendo um deles chamado Washing Day in Switzerland, de 1896, veiculando a marca de sabão Sunlight Soap junto a mulheres que lavavam suas roupas no filme.

Todavia, é senso comum de que o uso do placement se tornou intenso com o filme E.T. The Extra-Terrestrial, do diretor Steven Spielberg, de 1982. No filme, o ET seguia uma trilha feita com doces da marca Hershey's Reese's Pieces. Para colocar a sua marca no filme, a empresa Hershey's Inc. aceitou investir US\$ 1 milhão na época na promoção conjunta do E.T. e da sua marca Reese's Pieces. O sucesso de vendas foi tão assombroso que esse placement é citado por vários estudiosos como sendo o início da virada do desenvolvimento das práticas do placement e, claro, um dos exemplos que obteve maior sucesso, pois as vendas naquela época da marca Reese's Pieces triplicaram (Andriasova, 2006).

Atualmente, o placement está disseminado, inserido não somente em filmes, mas também em programas televisivos como, por exemplo, em seriados norte-americanos (Muzellec, Kanitz, \& Lynn, 2013; Russell, 2002), talk-shows ou mesmo em telejornais (Andriasova, 2006), ou ainda em jogos de videogame ou de computador (Herrewijn \& Poels, 2013) e até em músicas, livros e na Internet (Andriasova, 2006; Romaniuk, 2009).

Essa nova forma da comunicação, conhecida no Brasil erroneamente como merchandising, merchandising comercial (Boeing, Urdan, \& Gentry, 2013), merchandising televisivo (Trindade, 2007) ou de merchandising editorial (Blessa, 2009), que na verdade está focada na promoção de produtos e serviços nos próprios pontos de vendas (Shimp, 2002), é chamado de brand placement ou product placement e definida como sendo a inclusão paga de marcas de produtos ou de identificadores das marcas através de meios visuais e/ou sonoros na programação da mídia de massa (Karrh, 1998).

Portanto, o placement nada mais é do que uma comunicação de marketing indireto que, em termos gerais, tem o objetivo de gerar associações positivas em relação à marca veiculada, para resultar em uma mudança positiva na atitude de marca (Cowley \& Barron, 2008). Finalmente, 
Balasubramanian (1994) afirma que o placement é uma mensagem híbrida, ou seja, uma combinação de propaganda e publicidade. Isso porque o placement é normalmente pago pelo anunciante como acontece com a propaganda, mas não é identificado como um esforço de persuasão pago pelo anunciante como acontece com a publicidade.

Desta forma, o placement tem algumas vantagens com relação à propaganda tradicional. Em primeiro lugar, a inclusão de marcas no conteúdo da programação televisiva custa, normalmente, menos do que nos comerciais (Andriasova, 2006). Em segundo lugar, o placement auxilia os anunciantes a destacar suas marcas, pois tanto ele como elas não concorrem com os inúmeros comerciais que são veiculados nos intervalos dos programas televisivos (Andriasova, 2006). Em terceiro lugar, os telespectadores não conseguem evitar a exposição da marca no programa televisivo (Cowley \& Barron, 2008), pois ela está inserida no conteúdo do programa e, portanto, não é afetada pelas tecnologias atualmente existentes de zapping, zipping ou skipping.

A quarta vantagem do placement sobre a propaganda tradicional é que ele pode ser integrado tematicamente com o programa de TV muito mais facilmente do que a propaganda (Gupta \& Gould, 2007), em que as marcas são inseridas em contextos favoráveis, naturais e críveis, oferecendo aos anunciantes uma oportunidade única de formar associações favoráveis e de melhorar a imagem de suas marcas (Karrh, 1998; Reijmersdal, Neijens, \& Smit, 2007). Neste caso, o placement propicia ao anunciante apresentar o seu produto ao cliente no seu ambiente natural e também de como utilizá-lo (Andriasova, 2006). Caso a marca seja percebida pelo telespectador como estando presente no programa televisivo para deixá-lo mais realista - afinal, todos usam marcas no seu cotidiano, o real objetivo persuasivo da sua inserção estará oculta para o consumidor (Bhatnagar, Aksoy, \& Malkoc, 2004), ou seja, estará fora do seu radar das táticas comerciais normalmente utilizadas pelas empresas (Cowley \& Barron, 2008).

Finalmente, a quinta e última vantagem do placement frente à propaganda tradicional é que a marca veiculada dentro dos programas televisivos tem uma vida útil mais longa (Brennan, Dubas, \& Babin, 1999; D'Astous \& Chartier, 2000), porque um programa de TV normalmente é relançado em DVD, BluRay ou reapresentado na própria TV em vários momentos, fazendo com que a marca continue presente com a reexibição do programa.

Portanto, o placement alia os benefícios da propaganda e da publicidade mesmo não sendo completamente nem uma nem outro. Ou seja, apesar do anunciante ter controle limitado sobre a comunicação, já que está sujeita às decisões editoriais dos programas televisivos, esta pode não ser identificada explicitamente pelo telespectador como sendo persuasiva, já que o esforço para persuadir o consumidor não é saliente para a audiência do programa televisivo. Sendo assim, o placement se diferencia de outras ferramentas tradicionais de comunicação de marketing pela sua natureza de esconder o jogo ao telespectador, tanto sobre o nome do anunciante como sobre os objetivos reais da inserção da marca no programa televisivo (Balasubramanian, 1994).

Entretanto, o placement também possui algumas desvantagens, como a falta de controle do anunciante no que tange ao processo de inserção do placement no programa televisivo, por exemplo. Andriasova (2006) refere-se a um caso em que a marca esportiva Reebok investiu $\$ 10$ milhões de dólares para inserir sua marca no filme chamado Jerry Maguire, com Tom Cruise como ator de destaque, mas que, na versão final do filme, ela não apareceu por decisão do diretor do filme.

Outra possibilidade é a inserção da marca em um momento inadequado do programa ou ainda transmitir, sem querer, uma imagem negativa conforme o programa e a cena escolhidos para a inserção da marca. Foi o que aconteceu com a varejista K-Mart no filme Rain Man, em que numa discussão entre os atores Tom Cruise e Dustin Hoffman foi mencionada, de maneira desastrosa, o nome da empresa.

Por fim, questões éticas e morais podem ser mais facilmente indagadas devido à natureza do placement do que à propaganda tradicional (Andriasova, 2006). Por exemplo, Eisend (2009) afirma que a ideia de uma persuasão subliminar atribuída a um placement está fazendo com que determinadas 
organizações defensoras dos direitos dos consumidores e até políticas públicas criadas por certos países comecem a discutir limites na inserção de produtos em diversas mídias por acharem o placement um comportamento antiético. Todavia, tal percepção de aceitação ou não do placement pode mudar de cultura para cultura (Eisend, 2009) ou ainda ser semelhante em culturas um tanto diferentes no que se refere às atitudes e intenção de compra da marca inserida na mídia (Boeing et al., 2013).

Por ser destoante da propaganda tradicional, Balasubramanian (1994) sugere que os telespectadores podem processar o placement também de maneira diferente, aliada às características peculiares da sua natureza, tópico a seguir discutido.

\section{Dimensões do placement}

O placement tem sido classificado em várias dimensões, dependendo da natureza da sua utilização na tela da televisão. Por exemplo, Gupta e Lord (1998) propuseram uma abordagem bidimensional: a primeira dimensão é o modo de apresentação do placement, que pode ser visual, apenas sonoro ou audiovisual. Ou seja, o modo visual refere-se à marca sendo apenas visualmente mostrada na tela. Já o modo auditivo ou verbal refere-se à marca sendo apenas mencionada em diálogo, sem ter sido mostrada na tela. Por fim, o modo de apresentação audiovisual ocorre quando ambos foram inseridos na tela. Portanto, a dimensão do modo de apresentação refere-se aos sentidos que são ativados pelo estímulo visual, sonoro ou por ambos.

A segunda e última dimensão do placement, conforme Gupta e Lord (1998), é a proeminência, ou seja, a extensão na qual o placement possui características destinadas a torná-lo o foco central da atenção da audiência. A proeminência pode ser operacionalizada pelo tamanho do produto ou logotipo, pelo grau de centralização na tela, pela sua integração ou centralidade na estória do programa televisivo, pelo número de menções, pelo tempo de duração na tela, pela sua força, pela modalidade, dentre outros (Babin \& Carder, 1996; Bhatnagar et al., 2004; Gupta \& Lord, 1998; Law \& Braun, 2000; Russell, 2002).

Dessa forma, entende-se que o placement pode ser proeminente ou sutil, sendo o segundo caso quando a marca não é mostrada de maneira notável ou, como disse Homer (2009), não está na sua cara.

Tais categorizações são muito importantes, já que ambos os modos de apresentação e a proeminência são relevantes para facilitar com que a marca possa ser incorporada na programação televisiva e, por conseguinte, para o custo ao anunciante (Gupta \& Lord, 1998). Além disso, diferentes tipos de placement poderão causar diferentes reações no consumidor.

Outra dimensão da operacionalização do placement inspira-se no velho ditado de que pássaros de mesma pena voam juntos (tradução nossa do inglês para birds of a feather flock together) (Fleck \& Quester, 2007). Ou seja, o placement pode ser também operacionalizado segundo sua congruência. Nesse sentido, e reconhecendo que algumas coisas vão juntas, enquanto que outras se chocam, pesquisadores e profissionais da área de marketing têm estudado como e por que a congruência pode ajudar nas estratégias de marketing, seja por determinar quais extensões de marca podem ser almejadas, identificar qual celebridade a ser utilizada para endossar sua marca, ou ainda selecionar qual evento ou esporte patrocinar.

Nesse sentido, a literatura sobre patrocínio é interessante, por este ser semelhante ao placement em dois aspectos (Fleck \& Quester, 2007): primeiro, o seu processamento é periférico (Janiszewski, 1993), já que os consumidores atendem primeiro ao evento, à exposição ou ao concerto ao invés da mensagem em si; segundo, a mensagem é geralmente não verbal e mais implícita do que explícita (Tripodi, Hirons, Bednall, \& Sutherlan, 2003). Assim, cabe ao consumidor decifrar a mensagem e darlhe sentido, esperando, o patrocinador, que isso fortaleça as associações e o valor da sua marca. 
Por exemplo, D'Astous e Seguin (1999) dizem que há três tipos principais de estratégias de placement para o patrocínio televisivo: a implícita, a explícita integrada e a explícita não integrada: a primeira é aquela em que a marca, a empresa ou o produto está presente no programa, mas sem ser formalmente expressa: ela desempenha um papel passivo, contextual. A segunda é quando a marca ou a empresa está formalmente expressa dentro do programa: ela desempenha um papel ativo. E a terceira é aquela em que a marca ou a empresa está formalmente expressa, mas não é integrada ao conteúdo do programa.

Seguindo adiante, entende-se a congruência entre um placement e o programa televisivo conforme o grau em que o primeiro é tematicamente semelhante ao segundo, no qual está inserido (Zanjani et al., 2011). Por exemplo, marcas de produtos de pesca seriam congruentes se anunciados em programas televisivos de pesca, e incongruentes, se anunciados em programas de TV sobre culinária vegetariana.

Em outras palavras, a congruência entre propaganda e televisão depende do contexto entre ambos, sendo que a congruência emocional também pode ser importante nessa interação. Nesse sentido, existem estudos que mostram que pode haver diferenças ao consumidor quanto à marca anunciada se o programa televisivo é alegre ou triste ou, ainda, os estados afetivos preexistentes do consumidor podem afetar suas respostas ao contexto a ele ou ela apresentado (Batra \& Stayman, 1990). Entende-se, portanto, que a congruência pode estar relacionada também à similaridade de emoções e atitudes na interação entre o programa televisivo e as marcas.

\section{Teorias e estudos já realizados}

Segundo McCarty (2004), no nível mais básico, ou seja, quando o placement é veiculado de maneira singela visual ou sonoramente, o processo psicológico envolvido pode ser tão simples quanto um condicionamento clássico ou uma mera exposição. O primeiro significa que há um pareamento de um estímulo não condicionado (exemplo, uma paisagem bonita) com o condicionado (exemplo, uma marca). Dessa forma, as respostas positivas associadas com o estímulo não condicionado podem ser transferidas para o estímulo condicionado. Todavia, McCarty (2004) afirma que, se o condicionamento clássico fosse realmente o processo determinante para a eficácia do placement televisivo, complicações surgiriam, pois o telespectador apresenta diversos sentimentos (positivos e/ou negativos) no decorrer do programa de TV; portanto, seria um tanto árduo o trabalho de predizer a sua resposta frente à marca do produto anunciado dentro do programa televisivo.

Para tanto, talvez a mera exposição (Vollmers \& Mizerski, 1994) seja a solução. Ou seja, os telespectadores responderiam mais favoravelmente à determinada marca simplesmente por causa de sua exposição repetida à mesma. Ressalta-se, entretanto, que estudos sobre o placement pouco utilizaram a repetição como variável independente, à exceção de autores como Homer (2009) e Romaniuk (2009).

Finalmente, McCarty (2004) afirma que tanto o condicionamento clássico quanto a mera exposição dificilmente seriam as escolhas corretas quando o placement for mais complexo. Ou seja, e conforme Russell (2002), a conexão da marca com a estória do programa televisivo pode ser um complicador para o estudo das respostas do telespectador ao placement.

Segundo McCarty (2004), neste caso em que o placement está intimamente ligado ao personagem da história ou à história em si, o processamento poderia ocorrer de maneira transformacional, ou seja, a propaganda (transformacional) de certo produto ou marca transforma ou modifica a experiência de uso do produto fazendo com que este mesmo produto seja mais do que ele realmente é. De modo semelhante, a experiência de um telespectador no uso de uma marca pode ser transformada porque a marca está inserida em um show televisivo. Em outras palavras, o produto não é visto apenas em seu sentido funcional. Portanto, ele é endossado pelas características associadas ao programa televisivo. 
Seguindo adiante, o modelo de Petty e Cacioppo (1984) chamado de Elaboration Likelihood Model (ELM) também pode ser uma alternativa para explicar como o placement funciona. Esses autores afirmam que existem duas rotas distintas para a modificação das atitudes de um indivíduo quando processa uma mensagem de comunicação de marketing: se o consumidor tem motivação e habilidade, ele ativa a rota central de processamento da mensagem. Nesse caso, o consumidor presta atenção aos apelos e argumentos da mensagem, e tira conclusões sobre os seus méritos para, finalmente, avaliar ou responder com certa atitude à marca ou produto anunciado. Todavia, se a motivação ou a habilidade de processar a mensagem é baixa, a rota periférica é a que será ativada. Nesse caso, o consumidor não considera cuidadosamente o apelo ou o argumento da mensagem anunciada, mas se atém a pistas persuasivas, como o endosso de celebridades, por exemplo, para responder à marca ou ao produto anunciado. Tal ideia refere-se à propaganda tradicional.

Para o placement, deve-se ter em mente que a atenção do telespectador está direcionada para o programa televisivo; a compreensão do consumidor volta-se, portanto, para a estória do programa e para os personagens e não para os atributos do produto ou marca inseridos na tela. Ou seja, o telespectador não busca ativamente sobre informações do produto, sugerindo, portanto, que a formação da sua atitude sobre a marca inserida na tela siga a rota periférica de persuasão (Andriasova, 2006, Janiszewski, 1993). Como resultado, o consumidor não irá contra-argumentar ou avaliar criticamente a marca, mas a cena, a história, os personagens, etc, os quais são fontes positivas ou negativas para a formação da atitude do consumidor sobre a marca.

Contudo, é possível que o telespectador use a rota central da persuasão, dependendo das características do placement, principalmente quando este for proeminente e/ou incongruente com a estória ou com outras características do programa televisivo. Ou seja, um placement nada sutil ou fora de contexto pode fazer com que o consumidor contra-argumente e avalie criticamente a marca anunciada.

Para tanto, Friestad e Wright (1994) criaram o Persuasion Knowledge Model (PKM), focando em como indivíduos utilizam seus conhecimentos sobre as táticas persuasivas existentes no mundo para interpretar, avaliar e responder às mensagens de marketing. Com isso, tal conhecimento ajuda o consumidor a formar atitudes sobre o anunciante, o produto ou a marca anunciada. Seguindo adiante, a aceitação de uma mensagem persuasiva depende de o consumidor entender que essa mensagem é persuasiva ou não. Caso ele entenda que ela o é, de fato, persuasiva, o consumidor ativará certas táticas que o ajudarão a desviar a atenção para outras cenas. , voltando a prestar atenção na propaganda quando realmente quiser e procurar entender o motivo da marca ser anunciada naquele momento, além de quais seriam os objetivos do anunciante ou até mesmo do programa televisivo para anunciar determinada marca (Friestad \& Wright, 1994). Além disso, as reações à persuasão poderão ser diversas, afetando positiva ou negativamente as atitudes sobre a marca, sobre o anunciante e até sobre o programa televisivo. Finalmente, tais reações poderão, ainda, acarretar respostas comportamentais diversas.

O priming também pode ser útil para entender os efeitos do placement ao consumidor. O termo, para o presente caso, significa fornecer algum tipo de informação sobre a marca antes da sua exposição ao telespectador (Andriasova, 2006). Isso significa que a avaliação de um indivíduo sobre determinada marca, por exemplo, pode ser sensível ao contexto. Yi (1990) encontrou que uma exposição inicial a determinados fatores contextuais pode afetar certos atributos do produto e, subsequentemente, aumentar a probabilidade do consumidor interpretar as informações desse produto conforme tais atributos, afetando, por fim, a avaliação da marca anunciada.

Esse resultado foi encontrado para propagandas em mídia impressa, mas, se o programa televisivo for entendido como participante de um contexto, como será visto mais adiante, é possível que o priming possa ser também relevante para entender como um placement afeta o consumidor, como foi sugerido por Andriasova (2006) ao afirmar que um priming anterior ao placement televisivo pode fazer com que o telespectador note e se concentre mais na marca anunciada no programa de TV. Finalmente, o placement pode ser estudado a partir do input interference ao afirmar que a congruência 
entre o contexto e o objeto afeta negativamente a memória por causa dos efeitos de interferência (Malaviya, Meyers-Levy, \& Sternhal, 1999).

Além de tudo isso, acredita-se que o placement possa evocar o afeto. Sabe-se, por exemplo, que emoções específicas podem produzir efeitos nos consumidores, mesmo sem eles notarem que efetivamente transferiram as respostas emocionais e atitudinais a determinados tipos de comportamento (Cohen, Pham, \& Andrade, 2008). Ou seja, refere-se às respostas afetivas que são genuinamente experimentadas e diretamente ligadas ao objeto da decisão.

Ainda segundo os mesmos autores, existem estudos mostrando que objetos transmissores de sentimentos agradáveis como, por exemplo, uma celebridade querida pela audiência ou um programa televisivo cômico, são avaliados mais favoravelmente, e que objetos desagradáveis como, por exemplo, programas televisivos tristes, são avaliados menos favoravelmente. Ou seja, teorias como da congruência do humor (Kamins, Marks, \& Skinner, 1991) podem ser utilizados para explicar tal fenômeno. Ela afirma que o humor positivo criado pelo programa televisivo ativaria nodos prazerosos na memória, os quais afetariam positivamente a avaliação da propaganda e até mesmo a intenção de compra da marca anunciada, mesmo esta sendo negativa no sentido de ser dramática ou depressiva, como comerciais de ajuda a dependentes químicos, por exemplo. Ou seja, a transferência ocorreria do programa televisivo para a propaganda.

Outra teoria que pode ser útil é a de Krugman (1983), chamada de Hipótese Spillover, afirmando que programas televisivos apreciados (positiva) pela audiência podem aumentar a eficácia da propaganda, ao contrário do que afirmavam pesquisadores daquela época, de que, quanto mais apreciados um programa de TV, menos seriam os comerciais do mesmo, por interromperem o show. Portanto, em seu estudo, Krugman (1983) encontrou que programas televisivos interessantes ao telespectador podem aumentar a eficácia dos comerciais e vice-versa.

Finalmente, a teoria da transferência de afeto (McInnis \& Jaworski, 1989) sugere o mesmo, ou seja, que o afeto desencadeado por um estímulo pode afetar as respostas avaliativas a determinado objeto. Por exemplo, estímulos que evocam sentimentos negativos (positivos) terão impactos negativos (positivos) nas atitudes do consumidor sobre a marca. Portanto, é um condicionamento avaliativo que se refere à transferência de significado entre um estímulo e um objeto.

A seguir serão apresentados alguns estudos focados em placement e que, corroborados por muitas das teorias já mencionadas, servem de inspiração para a criação das proposições do presente estudo. Ressalva-se, todavia, que a forma de apresentar os estudos a seguir foi feita a partir do processamento de informação, com o intuito apenas de separar cada construto do modelo para melhor entendimento sem, necessariamente, ater-se tão somente a ele, como fizeram estudos levantados por Balasubramanian et al. (2006), Reijmersdal et al. (2009), e Kureshi e Sood (2010).

\section{Atenção (visual)}

Conforme a literatura tradicional, o processamento de informação inicia-se com a atenção, que pode ser definida como a alocação da capacidade de processamento a um estímulo (Engel, Blackwell, \& Miniard, 2000).

Nesse sentido, o levantamento feito por Reijmersdal et al. (2009) de estudos anteriores revela que poucas pesquisas têm usado a atenção como construto ao tratar do placement. Todavia, esses parcos estudos verificaram, por exemplo, que a atenção aumenta quando o placement tem um formato mais editorial ao invés de um formato mais comercial (Kim, Pasadeos, \& Barban, 2001; Lord \& Putrevu, 1998; Reijmersdal, Neijens, \& Smit, 2005). No entanto, ressalta-se que todos os estudos preocupados com a atenção no placement utilizaram questionários para a mensuração do construto.

Atualmente, pesquisas sobre a atenção encaram-na sob outra perspectiva: ao invés de serem apenas uma entrada ou simplesmente processos de armazenamento que traduzem o mundo visual lá de fora para o mundo afetivo-cognitivo daqui de dentro, os processos visuais têm um papel central na 
mente, conscientemente ou inconscientemente, e, portanto, influenciam diretamente o comportamento do consumidor (Wedel \& Pieters, 2008).

Seguindo adiante, a quantidade de informações que são transmitidas pelo nervo óptico excede em muito aquilo que o cérebro consegue processar. Portanto, o cérebro precisa se ater a mecanismos que selecionam informações relevantes para o processamento subsequente. Esse processo de seleção e focalização se chama atenção (Wedel \& Pieters, 2006).

Pode-se concluir que o modelo do processamento de informação e outros modelos existentes não são, em certa medida, adequados para entender a atenção em sua plenitude, porque esta é fundamental para o processamento da propaganda e, também, é uma propriedade emergente de todo o cérebro, ao invés de ser apenas o início do processamento da informação (Pieters \& Wedel, 2008).

Apesar de ainda escassos ou limitados (Wedel \& Pieters, 2006), estudos envolvendo o marketing visual se inserem na interseção entre a ciência da visão, a psicologia cognitiva e a psicologia social. Para a primeira, cujas raízes advêm da psicologia, da neurociência, da ciência da computação, da oftalmologia, da estética, entre outros, a ideia central é a de que a visão é a computação que ocorre no olho e no cérebro para construir uma representação do mundo que nos cerca (Wedel \& Pieters, 2008). Para a segunda - psicologia cognitiva - busca-se o entendimento da influência das características perceptuais dos estímulos nos processos da atenção e cognitivos. Finalmente, o marketing visual apresenta uma ligação entre a ciência da visão e a psicologia social, trazendo, esta última, teorias e métodos que almejam acessar e entender o papel da motivação e da emoção na visão (Wedel \& Pieters, 2008).

Para tanto, os movimentos dos olhos podem revelar informações importantes sobre os processos cognitivos, havendo a menção de que há uma relação forte entre para onde a pessoa está olhando com o que ela está pensando a respeito do que vê (Anderson, Bothell, \& Douglas, 2004). Ou seja, os movimentos dos olhos durante a exposição a uma determinada propaganda são indicadores fisiológicos da atenção.

Nesse sentido, Pieters, Rosbergen e Wedel (1999) afirmam que a atenção manifestada pelos movimentos motores observáveis dos olhos realiza um caminho a ser percorrido, podendo ser por fixação ou ainda por pulos (saccades). Estes últimos são os pulos rápidos que os olhos do consumidor fazem quando vão de um local a outro, enquanto que as fixações são as pausas que os olhos fazem entre um pulo e outro, ficando relativamente imóveis.

Dessa forma, Pieters et al. (1999) concluem que a fixação dos olhos é o modo mais eficiente para os humanos no que tange à obtenção de informação do ambiente no qual está inserido e, portanto, é o momento ideal para mensurar a atenção do consumidor.

Sendo assim, a atenção exercida pelo consumidor frente à determinada propaganda é capturada através da fixação dos olhos nos elementos de uma propaganda, como à marca, ao texto e à figura. $\mathrm{Ou}$ seja, por se tratar da mensuração da atenção do consumidor frente a uma propaganda, o importante é saber o número e a duração das fixações, relacionando com a quantidade de informação que o consumidor extrai da propaganda (Wedel \& Pieters, 2000).

Apesar de já haver estudos abordando a atenção visual a comerciais televisivos (Brasel \& Gips, 2008; Teixeira, Wedel, \& Pieters, 2010), ainda não há estudos dos efeitos do placement na atenção visual do consumidor. Nesse sentido, faltam estudos que mensurem a atenção visual no placement, inclusive nos pop-up ads.

Como foi visto anteriormente, os pop-up ads podem ser considerados placements, por serem visualizados pelo telespectador no mesmo instante que o show televisivo. Sendo assim, entende-se que eles também possuam dimensões semelhantes ao placement. Nesse sentido, a proeminência pode ser verificada nos pop-ups com a mesma intenção de torná-los o foco central da atenção da audiência (Gupta \& Lord, 1998). Conforme o que foi visto até aqui, um placement pode ser proeminente ou sutil, sendo que há estudos sobre o assunto, mas que não abordam a atenção visual sobre o mesmo. 
Todavia, e assim como Gupta e Lord (1998), Reijmersdal et al. (2009) afirmam, citando alguns estudos anteriores, que possivelmente haverá um processamento periférico da atenção a um placement (Janiszewski, 1993), já que o mesmo não é o foco da atenção do consumidor. Portanto, entende-se que um pop-up proeminente afetará a atenção do telespectador muito mais do que um pop-up sutil, ratificando o fato de suas características realmente tentarem desviar o foco da atenção do telespectador do show televisivo para a propaganda no mesmo instante apresentada.

Por tudo isso, criou-se a seguinte proposição de pesquisa:

$\mathbf{P}_{\mathbf{1 a}}$ : Quanto mais proeminente for o pop-up ad inserido no programa televisivo, maior será a atenção visual do consumidor ao mesmo.

Com relação à congruência, a ideia é também semelhante ao placement tradicional. Ou seja, um pop-up ad será congruente quando houver uma forte ligação entre o patrocinador e o patrocinado (Zanjani et al., 2011); em outras palavras, entre a marca anunciante e o programa televisivo. E, conforme o que já foi mostrado, os efeitos da congruência são similares ao da proeminência, pois se entende que haja pouca atenção a um pop-up ad que não se choca com o show de TV (Zanjani et al., 2011). Sendo assim, a proposição é a seguinte:

$\mathbf{P}_{2 \mathrm{a}}$ : Quanto menos congruente for o pop-up ad inserido no programa televisivo, maior será a atenção visual do consumidor ao mesmo.

Sob uma visão gerencial, as proposições acima desenvolvidas sugerem que uma empresa deve, se a intenção for a de chamar a atenção do consumidor para a marca inserida como pop-up ad televisivo, veiculá-la de maneira mais proeminente ou incongruente possível para que o consumidor note a marca enquanto estiver assistindo ao programa televisivo.

\section{Memória}

Para Wedel e Pieters (2000), a memorização da informação disponibilizada pela propaganda é importante. Isso porque, segundo eles, uma propaganda dita efetiva será aquela que atrair a atenção do consumidor e deixar traços da marca incrustados na memória do consumidor. Ou seja, a atenção visual somente não leva em conta a questão do armazenamento da informação na memória.

Conforme o processamento de informação mencionado anteriormente, a memória, de maneira bem resumida e prática, envolve tudo aquilo de que o consumidor se lembra (reconhece e recorda) sobre os estímulos de marketing, e como ele acessa e recupera essas informações ao fazer as escolhas de consumo (Shimp, 2002). Para tanto, a memória divide-se em três: a de longo prazo, a de curto prazo e a sensorial. Nesta última, "a informação que chega recebe uma análise inicial fortemente baseada em propriedades físicas" (Engel et al., 2000, p. 326), ou seja, refere-se ao processamento visual e ao auditivo. Em seguida, passando pelo processamento sensorial, o estímulo entra na memória de curto prazo, na qual atua como o centro da atividade atual de processamento ao integrar a informação dos sentidos e da memória de longo prazo (Shimp, 2002). Todavia, a memória de curto prazo tem capacidade limitada de processamento, o que não acontece com a memória de longo prazo, descrita por psicólogos como sendo um armazém virtual de informações ilimitadas (Shimp, 2002).

Pesquisas sobre os efeitos da propaganda tradicional na memorização dos seus estímulos, principalmente na memória de curto prazo, são inúmeras. Além disso, já existem trabalhos sobre a memória no que se refere ao placement. Por exemplo, estudos encontraram que a proeminência de um placement tem um impacto positivo sobre a lembrança da marca anunciada do que um placement sutil (Babin \& Carder, 1996; Brennan et al., 1999; D'Astous \& Chartier, 2000; Gupta \& Lord, 1998; Law \& Braun, 2000). Isso porque, segundo Reijmersdal (2009), há um processamento mais intenso do placement proeminente do que de um placement sutil, aumentando, consequentemente, a memorização pelo consumidor. 
Outro resultado encontrado por estudos anteriores é que o placement sonoro ocasiona maior lembrança (Gupta \& Lord, 1998) e reconhecimento (Russell, 2002) do que placement visual, mas menor do que placement audiovisual (Gupta \& Lord, 1998). Portanto, se o foco do anunciante está na memorização, a escolha acertada seria o placement audiovisual.

Por tudo isso, entende-se também que os pop-ups, por serem placement, sejam semelhantes no que se refere aos potenciais resultados das dimensões mencionadas anteriormente. Ou seja, que um pop-up ad proeminente tenha um impacto mais positivo sobre a lembrança da marca anunciada do que um sutil, assim como foi encontrado em placement (Babin \& Carder, 1996; Brennan et al., 1999; D'Astous \& Chartier, 2000; Gupta \& Lord, 1998; Law \& Braun, 2000). Com isso, estabeleceu-se a próxima proposição de pesquisa:

$\mathbf{P}_{\mathbf{1 b}}$ : Quanto mais proeminente for o pop-up ad inserido no programa televisivo, maior será a memorização do consumidor ao mesmo.

Com relação à congruência, Russell (2002) descobriu, por exemplo, que a memória é intensificada quando a modalidade e a conexão com a história são incongruentes, mas a persuasão é reforçada pela congruência. É isso o que diz a literatura sobre incongruência, ou seja, que embora haja pouca elaboração quando a informação é congruente, na incongruência a elaboração cognitiva é acionada. Como resultado, a informação incongruente é memorável porque ele pede a atenção devida e provoca elaboração (Balasubramanian, Karrh, \& Patwardhan, 2006; Kureshi \& Sood, 2010; Reijmersdal, Neijens, \& Smit, 2009). É o que, por exemplo, D’Astous e Chartier (2000) encontraram em seu estudo: quanto menor a integração entre um placement e a mídia, maior será a memorização do placement.

Por isso, a próxima proposição é a seguinte:

$\mathbf{P}_{2 \mathbf{b}}$ : Quanto menos congruente for o pop-up ad inserido no programa televisivo, maior será a memorização do consumidor ao mesmo.

Sob a perspectiva gerencial, e assim como aconteceu com a atenção visual, as proposições acima desenvolvidas sugerem que a empresa deva investir em pop-up ads proeminentes ou incongruentes para que o consumidor memorize a marca anunciada de forma mais intensa.

\section{Atitudes}

Engel, Blackwell e Miniard (2000, p. 369) afirmam que "a capacidade da propaganda de criar atitudes favoráveis em relação a um produto geralmente pode depender das atitudes dos consumidores em relação ao próprio anúncio". Ou seja, a propaganda que for apreciada ou avaliada favoravelmente pode levar a atitudes de produto mais positivas e vice-versa. Assim, "atitudes são predisposições aprendidas a responder a um objeto ou a uma classe de objetos de forma consistentemente favorável ou desfavorável" (Sheth, Mittal, \& Newman, 2001, p. 367). Segundo Schiffman e Kanuk (1997), a palavra objeto, neste contexto, pode ser interpretada como sendo produto, categoria de produto, serviço, marca, uso do produto, pessoas, propaganda, preço, etc.

Nesse sentido, destaca-se que uma melhoria na memória não garante uma melhoria na atitude do consumidor (Reijmersdal, 2009). De fato, a falta de conscientização do consumidor de que a inclusão da marca é uma tentativa de influenciar sua atitude sobre a marca é essencial para a eficácia do placement (Bhatnagar et al., 2004). Assim, a marca pode ser positiva, neutra ou negativa para o consumidor. Por exemplo, alguns estudos não encontraram diferenças significativas sobre as atitudes da marca pelos participantes quando expostos ao placement ou por aqueles que não foram expostos ao placement (Vollmers \& Mizerski, 1994).

Todavia, o aumento do processamento acompanhado pela proeminência pode acarretar um efeito negativo em espaços em que um placement proeminente ou na sua cara pode inibir a persuasão se ele for percebido como sendo distrativo, irritante ou desagradável (D'Astous \& Chartier, 2000; 
Homer, 2009). Isso pode acontecer porque um placement proeminente pode ativar a consciência do espectador sobre a marca anunciada e acionar defesas cognitivas contra a persuasão pelo indivíduo (Friestad \& Wright, 1994). Então, quando expostos a um placement proeminente, os telespectadores podem entender que a marca está presente na mídia apenas por razões de persuasão e, com isso, ativam suas defesas cognitivas contra talmarca anunciada.

Mesmo assim, alguns estudos, como o de Russell (2002), encontraram atitudes positivas sobre a marca anunciada. E outros, mais preocupados com as atitudes sobre o programa de TV que anunciava o placement, descobriram que elas ficam negativas com a proeminência do placement (Homer, 2009). Destarte, os estudos referindo-se à atitude de marca são ainda contraditórios (Balasubramanian et al., 2006), mas acredita-se que pop-ups possam, assim como um placement, ativar o radar dos estímulos persuasivos informados por Friestad e Wright (1994), principalmente quando a propaganda for proeminente do que sutil. Portanto, a proposição a seguir é apresentada:

$\mathbf{P}_{1 \mathrm{c}}$ : Quanto mais proeminente for o pop-up ad inserido no programa televisivo, mais negativas serão as atitudes do consumidor aos mesmos.

Com relação à congruência, Russell (2002) descobriu que a persuasão é reforçada pela congruência. Ou seja, evidências empíricas suportam o fato de que a intensa elaboração associada com a incongruência extrema tem um efeito adverso sobre as avaliações do consumidor (Meyers-Levy \& Tybout, 1989). De fato, enquanto aumenta a atenção para o placement, a incongruência também acionará nos telespectadores divagações sobre a razão da presença da marca no programa televisivo, por exemplo. E isso pode levar o consumidor a usar mecanismos corretivos, como a contraargumentação, ou reações negativas, se o placement for percebido como inadequado (Friestad \& Wright, 1994). Portanto, enquanto o placement congruente pode ser percebido como aceitável, o incongruente pode suscitar suspeita nos telespectadores e reações negativas à marca.

É por isso que Russell (2002) encontrou que o placement congruente parece ser mais natural, enquanto que o incongruente afeta negativamente as atitudes do telespectador sobre a marca, porque ela parece fora de lugar. Então, entende-se que o efeito seja semelhante ao que acontece com a variável da proeminência.

D'Astous e Seguin (1999) dizem também que vários estudos têm demonstrado a importância de uma forte ligação entre o patrocinador e o evento ou entidade patrocinada: quanto mais forte essa ligação, maior o impacto na imagem do patrocinador e nas atitudes em relação ao patrocínio em si. Estendendo este achado para o placement televisivo, uma forte congruência entre patrocinador e programa de TV implica que os produtos e atividades do patrocinador estão claramente relacionados com o conteúdo do programa. Neste caso, o placement seria considerado mais natural e consistente com o âmbito do show televisivo. Todavia, uma fraca congruência entre patrocinador e programa televisivo pode deixar o placement inconsistente e sem credibilidade. $\mathrm{O}$ mesmo pode ser entendido para os pop-up ads. Portanto, a proposição de pesquisa é a seguinte:

$\mathbf{P}_{2 \mathrm{c}}$ : Quanto menos congruente for o pop-up ad inserido no programa televisivo, mais negativas serão as atitudes do consumidor aos mesmos.

Conforme destacado na teoria, entende-se que possa haver uma congruência do afeto frente a determinado contexto; ou seja, os efeitos que um programa televisivo alegre ou triste teria sobre a propaganda ou a marca ao consumidor. Por exemplo, Krugman (1983) já dizia que programas televisivos que são queridos ou que criam reações positivas nos telespectadores podem ajudar na efetividade dos comerciais, havendo, portanto, uma transferência de afeto do programa televisivo aos comerciais, corroborados também por outros estudos (Batra \& Stayman, 1990; Martin, 2003; McInnis \& Jaworski, 1989).

O mesmo afirmaram Goldberg e Gorn (1987), por exemplo, que encontraram que, quando um programa televisivo a que pessoas assistiram evoca afeto positivo, a resposta dos participantes às propagandas é muito mais positiva do que quando o programa evoca afeto negativo. Ou seja, o tipo de 
afeto manifestado ao assistir a um programa televisivo encoraja no consumidor determinadas respostas cognitivas de mesma valência (Mathur \& Chattopadhyay, 1991).

Portanto, sabe-se que o afeto influencia as avaliações do consumidor, principalmente na direção do programa televisivo para a propaganda. Todavia, vale ressaltar que os estudos anteriores se preocuparam em entender como isso afeta o consumidor frente às propagandas que foram veiculadas separadamente aos programas televisivos. Ou seja, não se sabe, até o presente momento, como (ou se) o afeto poderia incorrer em certos efeitos se a propaganda estivesse inserida no programa televisivo. Nesse caso, e conforme os levantamentos feitos por Balasubramanian et al. (2006), Reijmersdal et al. (2009), e Kureshi e Sood (2010), pouco se sabe sobre essa questão da transferência do afeto no placement televisivo. Uma exceção é o estudo de placement reverso de Muzellec, Kanitz e Lynn (2013), cujo foco foi o de analisar os efeitos das atitudes de marcas ficcionais a partir das atitudes dos consumidores sobre os programas televisivos. Apesar de serem marcas existentes em programas televisivos como, por exemplo, o bar chamado Central Perk do seriado Friends, os autores do estudo encontraram que atitudes favoráveis ao respectivo show televisivo afetaram positivamente nas atitudes sobre as marcas fictícias, e que tais resultados podem influenciar positivamente na intenção de compra do produto, caso seja lançado no mercado.

Seguindo adiante, e se forem levados em consideração os resultados dos estudos mencionados anteriormente, e se o mesmo efeito acontecer aos pop-up ads, então acredita-se que a proposição seja a seguinte:

$\mathbf{P}_{3}$ : Quanto mais positiva for a atitude ao programa televisivo, mais positivas serão as atitudes do consumidor sobre as marcas anunciadas no mesmo.

Todavia, por ambos - programa televisivo e placement - estarem no mesmo local ao mesmo tempo, quer dizer, são exibidos no mesmo momento ao telespectador, indaga-se, como fizeram Brasel e Gips (2008), se não haveria a possibilidade de existir uma transferência inversa de afeto nessa relação entre o programa televisivo e as marcas anunciadas; nesse caso, será que as marcas inseridas no programa televisivo podem afetar (positiva ou negativamente) as atitudes ao show a que o consumidor assistiu?

Nesse sentido, explorou-se essa questão inédita através da seguinte proposição de pesquisa:

$\mathbf{P}_{4}$ : Quanto mais positivas forem as atitudes às marcas anunciadas no programa televisivo, mais positivas serão as atitudes do consumidor sobre o programa televisivo.

Sob uma visão gerencial, as proposições anteriormente desenvolvidas sugerem que uma empresa deva, se o objetivo for a de fazer com que o consumidor tenha atitudes positivas sobre a marca inserida como pop-up ad televisivo, veiculá-la de maneira mais ou menos proeminente ou incongruente possível para que o consumidor não indague sobre os reais motivos da presença da marca no show de TV (Friestad \& Wright, 1994). E, finalmente, veicular a marca em programas afetivamente positivos para o consumidor.

\section{Intenção de compra}

Segundo Mowen e Minor (1998), intenção é um julgamento subjetivo em relação ao comportamento potencial futuro de determinado indivíduo no que tange a aquisição, disposição e uso de produtos e serviços.

Nesse sentido, uma das intenções existentes e exercidas pelo consumidor é o de compra, que representa - como o próprio nome diz - o que e qual o local em que os consumidores pretendem comprar. $\mathrm{Na}$ escolha da alternativa certa, é imperativo dizer que o consumidor é influenciado por diversas questões, e uma delas pode ser a influência situacional, como é o caso da propaganda (Engel et al., 2000; Shimp, 2002). 
Balasubramanian et al. (2006), Reijmersdal et al. (2009) e Kureshi e Sood (2010) encontraram em suas revisões sobre o tema poucos estudos concernentes ao comportamento de compra do consumidor. Por exemplo, estudos descobriram que a intenção de compra ou de revisitar um site foi mais positiva após a exposição do placement que foi divulgado com um formato mais editorial do que comercial (Becker-Olsen, 2003). E Law e Braun (2000) e Lord e Putrevu (1998) constataram que o comportamento e as intenções foram mais afetados pelos placement visuais ou sonoros do que por placement audiovisuais, ao contrário, portanto, do que acontece com a memorização, discutido anteriormente. Finalmente, Balasubramanian et al. (2006) dizem que, mesmo que a memória explícita não seja ativada e/ou os resultados afetivos se mantenham inalterados, a recente exposição à marca anunciada por placement pode fazer com que o consumidor a inclua na sua análise ou mesmo na sua escolha de compra.

Todavia, alguns estudos anteriormente abordados e que utilizaram o Persuasion Knowledge Model (PKM) de Friestad e Wright (1994) em suas análises encontraram que a intenção de compra de determinada marca anunciada segue a mesma valência das atitudes. Logicamente, se um consumidor apresenta uma atitude negativa sobre uma marca ou produto, a sua intenção de compra diminuiria, salvo situações atípicas de mercado. E como a proeminência e a congruência afetam o consumidor em suas atitudes de maneira similar, entende-se que, para os pop-ups, os efeitos sejam também semelhantes. Nesse sentido, apresentam-se as seguintes proposições de pesquisa:

$\mathbf{P}_{\mathbf{1 d}}$ : Quanto mais proeminente for o pop-up ad inserido no programa televisivo, menor será a intenção de compra pelo consumidor da marca anunciada.

$\mathbf{P}_{2 \mathrm{~d}}$ : Quanto menos congruente for o pop-up ad inserido no programa televisivo, menor será a intenção de compra pelo consumidor da marca anunciada.

Por tudo isso, apresentam-se os modelos teóricos a seguir:

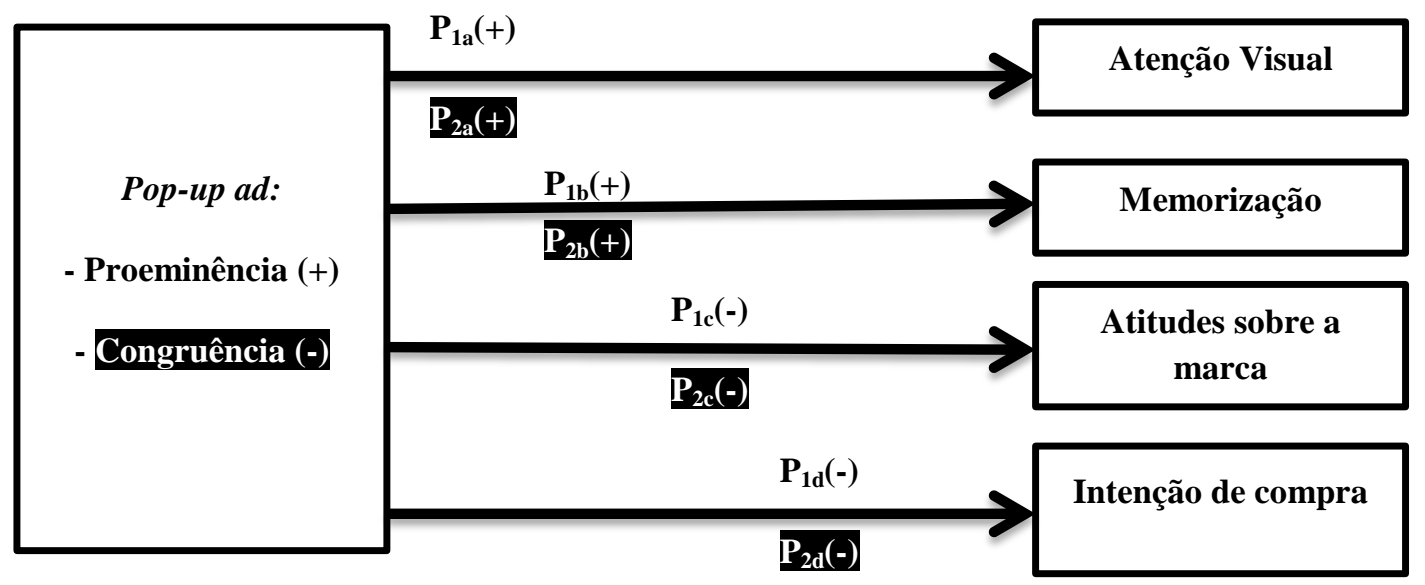

Figura 1. Primeiro Modelo Teórico.

Fonte: desenvolvido pelos autores.

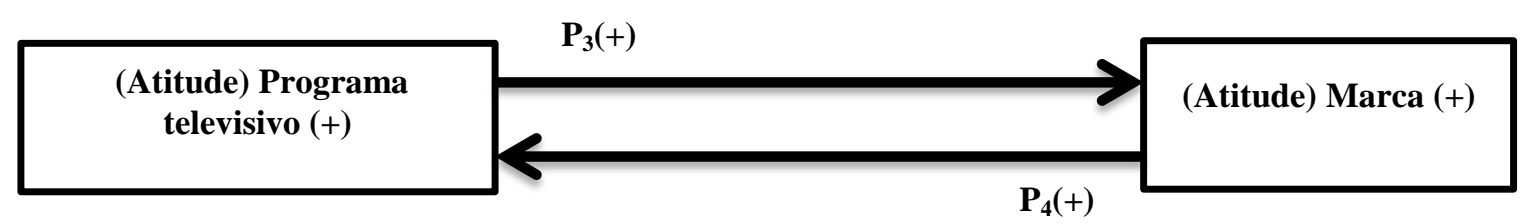

Figura 2. Segundo Modelo Teórico.

Fonte: Desenvolvido pelos autores. 


\section{Considerações Finais}

A partir de um ensaio teórico, foram estabelecidas proposições para pesquisas futuras ratificarem ou retificarem se os pop-up ads realmente afetam o comportamento do consumidor, já que ainda não há estudos que abordem esse tipo de placement na mídia televisiva.

Nesse sentido, sugere-se que sejam feitos estudos que investiguem uma ou mais proposições mencionadas anteriormente, principalmente através de pesquisas causais com o intuito de verificar as relações de causa e efeito entre as dimensões dos pop-up ads e as variáveis contidas no processamento de informação. E, finalmente, e assim como foi feito por Teixeira, Wedel e Pieters (2010) e por Brasel e Gips (2008), sugere-se que a atenção visual seja estudada com o auxílio da tecnologia do eye tracking, assegurando, pela movimentação dos olhos do consumidor, se ele realmente prestou atenção a um pop-up ad televisivo ou não.

Concluindo, e a partir dos resultados a serem encontrados por pesquisas futuras, informa-se que os profissionais responsáveis pelas práticas publicitárias podem precisar ter certo cuidado com o uso de pop-up ads inseridos em programas televisivos, principalmente se em tal uso, e conforme as dimensões utilizadas, for comprovado que há a ativação do Persuasion Knowledge Model (Friestad \& Wright, 1994). Portanto, o presente artigo tem o mérito de trazer à tona para a Academia a necessidade de se estudar um tipo de placement que há tempos está sendo veiculado na mídia televisiva pelo mundo gerencial: o pop-up ad.

\section{Agradecimentos}

Os autores agradecem ao Prof. Stevan Adam Brasel, da Boston College, EUA, por aceitar a ida do primeiro autor a sua instituição, bem como por auxiliar os autores na pesquisa. Em particular, o primeiro autor agradece pelo apoio financeiro da CAPES pelo Programa de Fomento à Pós-Graduação (PROF) e pelo Programa de Doutorado no País com Estágio no Exterior (PDEE), durante o período em que esteve realizando o Doutorado em Administração pela Universidade Federal do Paraná (UFPR).

\section{Nota}

\footnotetext{
${ }^{1}$ No Brasil, podem ainda ser encontrados termos como merchandising comercial (Boeing et al., 2013), merchandising televisivo (Trindade, 2007) e merchandising editorial (Blessa, 2009). Todavia, pela natureza do termo merchandising ser destoante da de placement, ratifica-se o uso do segundo como sendo o termo mais adequado para caracterizar a inserção de produtos e marcas em mídias.
}

\section{Referências}

Anderson, J. R., Bothell, D., \& Douglas, S. (2004). Eye movements do not reflect retrieval processes. Psychological Science, 15(4), 225-231. doi: 10.1111/j.0956-7976.2004.00656.x

Andriasova, A. (2006). They placed, I saw, I was conquered: evaluating the effects of persuasion knowledge and prominence of brand placement on viewers' attitudes and behavior (Doctoral dissertation). University of Texas at Austin, Austin, Texas, EUA.

Babin, L., \& Carder, S. (1996). Viewers' recognition of brands placed within a film. International Journal of Advertising, 15(2), 140-151. 
Balasubramanian, S. K. (1994). Beyond advertising and publicity: hybrid messages and public policy issues. Journal of Advertising, 23(4), 29-46. doi: 10.1080/00913367.1943.10673457

Balasubramanian, S. K., Karrh, J. A., \& Patwardhan, H. (2006). Audience response to product placements: an integrative framework and future research agenda. Journal of Advertising, 35(3), 115-141. doi: 10.2753/JOA0091-3367350308

Batra, R., \& Stayman, D. M. (1990). The role of mood in advertising effectiveness. Journal of Consumer Research, 17(2), 203-214. doi: 10.1086/20855

Becker-Olsen, K. (2003). And now a word from our sponsor: a look at effects of sponsored content and banner advertising. Journal of Advertising, 32(2), 17-32.

Bhatnagar, N., Aksoy, L., \& Malkoc, S. (2004). Embedding brands within media content: the impact of message, media, and consumer characteristics on placement efficacy. In L. Shrum (Org.), The psychology of entertainment media: the blurring of the lines between entertainment and persuasion (pp. 99-116). New Jersey: Lawrence Erlbaum.

Blessa, R. (2009). Merchandising no ponto de venda. São Paulo: Atlas.

Boeing, R., Urdan, A. T., \& Gentry, J. W. (2013). I saw it in the movies, but does that matter? Product placement in a cross cultural study between Brazil and The USA. Revista Brasileira de Marketing 12(1), 1-28. doi: 10.5585/remark.v12i2.2507

Brasel, S. A., \& Gips, J. (2008). Breaking through fast-forwarding: brand information and visual attention. Journal of Marketing, 72(6), 31-48. doi: 10.1509/jmkg.72.6.31

Brennan, L., Dubas, M., \& Babin, L. (1999). The influence of product placement type and exposure time on product placement recognition. International Journal of Advertising, 18(3), 323-337.

Cohen, J., Pham, M., \& Andrade, E. (2008). The nature and role of affect in consumer behavior. In C. Haugtvedt, F. Kardes, \& P. Herr (Orgs.), Handbook of consumer psychology (pp. 297-348). New Jersey: Erlbaum.

Cowley, E., \& Barron, C. (2008). When product placement goes wrong: the effects of program liking and placement prominence. Journal of Advertising, 37(1), 89-98. doi: 10.2753/JOA00913367370107

D'Astous, A., \& Chartier, F. (2000). A study of factors affecting consumer evaluations and memory of product placements in movies. Journal of Current Issues and Research in Advertising, 22(2), 31-40. doi: 10.1080/10641734.2000.10505106

D'Astous, A., \& Seguin, N. (1999). Consumer reactions to product placement strategies in television sponsorship. European Journal of Marketing, 33(9/10), 896-911. doi: $10.1108 / 03090569910285832$

Davenport, T., \& Beck, J. (2001). The attention economy: understanding the new currency of business. Boston: Harvard Business School Press.

Eisend, M. (2009). A cross-cultural generalizability study of consumers' acceptance of product placements in movies. Journal of Current Issues and Research in Advertising, 31(1), 15-25. doi: $10.1080 / 10641734.2009 .10505254$

Elpers, J. L. C. M. W., Wedel, M., \& Pieters, R. G. M. (2003). Why do consumers stop viewing television commercials? Two experiments on the influence of moment-to-moment entertainment and information value. Journal of Marketing Research, 40(4), 437-453. doi: 10.1509/jmkr.40.4.437.19393 
Engel, J. F., Blackwell, R. D., \& Miniard, P. W. (2000). Comportamento do consumidor (8a ed.). Rio de Janeiro: LTC.

Fleck, N., \& Quester, P. (2007). Birds of a feather flock together: definition, role and measure of congruence: an application to sponsorship. Psychology \& Marketing, 24(11), 975-1000. doi: $10.1002 /$ mar.20192

Friestad, M., \& Wright, P. (1994). The persuasion knowledge model: how people cope with persuasion attempts. Journal of Consumer Research, 21(1), 1-31. doi: 10.1086/209380

Goldberg, M. E., \& Gorn, G. J. (1987). Happy and sad TV programs: how they affect reactions to commercials. Journal of Consumer Research, 14(3), 387-403. doi: 10.1086/209122

Gupta, P. B., \& Gould, S. J. (2007). Recall of products places as prizes versus commercials in game shows. Journal of Current Issues and Research in Advertising, 29(1), 43-53. doi: 10.1080/10641734.2007.10505207

Gupta, P. B., \& Lord, K. R. (1998). Product placements in movies: the effect of prominence and mode on audience recall. Journal of Current Issues and Research in Advertising, 20(1), 47-59. doi: 10.1080/10641734.1998.10505076

Herrewijn, L., \& Poels, K. (2013). Putting brands into play: How game difficulty and player experiences influence the effectiveness of in-game advertising. International Journal of Advertising, 32(1), 17-44.

Homer, P. M. (2009). Product placements: the impact of placement type and repetition on attitude. Journal of Advertising, 38(3), 21-31. doi: 10.2753/JOA0091-3367380302

Janiszewski, C. (1993). Pre-attentive mere exposure effects. Journal of Consumer Research, 20(3), 376-392. doi: $10.1086 / 209356$

Kamins, M. A., Marks, L. J., \& Skinner, D. (1991). Television commercial evaluation in the context of program induced mood: congruency versus consistency effects. Journal of Advertising, 20(2), 1-14. doi: 10.1080/00913367.1991.10673209

Karrh, J. A. (1998). Brand placement: a review. Journal of Current Issues and Research in Advertising, 20(2), 31-49. doi: 10.1080/10641734.1998.10505081

Kim, B., Pasadeos, Y., \& Barban, A. (2001). On the deceptive effectiveness of labeled and unlabeled advertorial formats. Mass Communication and Society, 4(3), 265-281. doi: 10.1207/S15327825MCS0403_02

Krugman, H. (1983). Television program interest and commercial interruption: are commercials on interesting programs less effective? Journal of Advertising Research, 23(1), 21-23.

Kureshi, S., \& Sood, V. (2010). A review of placement literature: conceptual and managerial implications. Journal of Marketing Management, 9(1/2), 23-39.

Law, S., \& Braun, K. A. (2000). I'll have what she's having: gauging the impact of product placements on viewers. Psychology \& Marketing, 17(12), 1059-1075. doi: 10.1002/15206793(200012)17:12<1059::AID-MAR3>3.0.CO;2-V

Lord, K. R., \& Putrevu, S. (1998). Communicating in print: a comparison of consumer responses to different promotional formats. Journal of Current Issues and Research in Advertising, 20(2), 118. doi: 10.1080/10641734.1998.10505079 
Malaviya, P., Meyers-Levy, J., \& Sternhal, B. (1999). Ad repetition in a cluttered environment: the influence of type of processing. Psychology \& Marketing, 16(2), 99-118. doi: CCC07426046/99/020099-20

Martin, B. A. S. (2003). The influence of gender on mood effects in advertising. Psychology \& Marketing, 20(3), 249-273. doi: 10.1002/mar.10070

Mathur, M., \& Chattopadhyay, A. (1991). The impact of moods generated by television programs on responses to advertising. Psychology \& Marketing, 8(1), 59-77. doi: 10.1002/mar.4220080106

McCarty, J. (2004). Product placement: the nature of the practice and potential avenues of inquiry. In L. Shrum (Org.), The psychology of entertainment media: the blurring of the lines between entertainment and persuasion (pp. 45-62). New Jersey: Lawrence Erlbaum.

McInnis, D. J., \& Jaworski, B. J. (1989). Information processing from advertisements: toward an integrative framework. Journal of Marketing, 53(4), 1-23.

Meyers-Levy, J., \& Tybout, A. M. (1989). Schema congruity as a basis for product evaluation. Journal of Consumer Research, 16(1), 39-54. doi: 10.1086/209192

Mowen, J., \& Minor, M. (1998). Consumer behavior (5th ed.). New Jersey: Prentice Hall.

Muzellec, L., Kanitz, C., \& Lynn, T. (2013). Fancy a coffee with Friends in 'Central Perk'? Reverse product placement, fictional brands and purchase intention. International Journal of Advertising, 32(3), 399-417.

Newell, J., Salmon, C., \& Chang, S. (2006). The hidden history of product placement. Journal of Broadcasting and Electronic Media, 50(4), 575-594. doi: 10.1207/s15506878jobem5004_1

NYDailyNews.com. (2007, October 31). TV's new space invaders: popup ads. Recuperado de http://www.nydailynews.com/entertainment/tv-movies/tv-new-space-invaders-popup-adsarticle-1.227815

Petty, R., \& Cacioppo, J. (1984). Source factors and the elaboration likelihood model. Advances in Consumer Research, 11(1), 668-672.

Pieters, R., Rosbergen, E., \& Wedel, M. (1999). Visual attention to repeated print advertising: a test of scanpath theory. Journal of Marketing Research, 36(4), 424-438. doi: 10.2307/3151998

Pieters, R., \& Wedel, M. (2004). Attention capture and transfer in advertising: brand, pictorial, and text-size effects. Journal of Marketing, 68(2), 36-50. doi: 10.1509/jmkg.68.2.36.27794

Pieters, R., \& Wedel, M. (2008). Informativeness of eye movements for visual marketing: six cornerstones. In M. Wedel \& R. Pieters (Org.), Visual marketing: from attention to action (pp. 43-71). New York: Psychology Press.

PQ Media. (n.d.). PQ media global product placement spending forecast 2012-2016. Recuperado de http://www.pqmedia.com/globalproductplacementforecast-2012.html

Reijmersdal, E. M. A. van (2009). Brand placement prominence: good for memory! Bad for attitudes? Journal of Advertising Research, 49(2), 151-153.

Reijmersdal, E. M. A. van, Neijens, P., \& Smit, E. (2005). Readers' reactions to mixtures of advertising and editorial content in magazines. Journal of Current Issues and Research in Advertising, 27(2), 39-53. doi: 10.1080/10641734.2005.10505180

Reijmersdal, E. M. A. van, Neijens, P., \& Smit, E. (2007). Effects of TV brand placement on brand image. Psychology and Marketing, 24(5), 403-420. doi: 10.1002/mar.20166 
Reijmersdal, E. M. A. van, Neijens, P., \& Smit, E. (2009). A new branch of advertising: reviewing factors that influence reactions to product placement. Journal of Advertising Research, 49(4), 429-449. doi: 10.2501/S0021849909091065

Romaniuk, J. (2009). The efficacy of brand-execution tactics in TV advertising, brand placements, and internet advertising. Journal of Advertising Research, 49(2), 143-150. doi: $10.2501 / \mathrm{S} 0021849909090187$

Russell, C. (2002). Investigating the effectiveness of product placements in television films: the role of modality and plot connection congruence on brand memory and attitude. Journal of Consumer Research, 29(3), 306-318.

Sacharin, K. (2001). Attention! How to interrupt, yell, whisper, and touch consumers. New York: John Wiley \& Sons.

Schiffman, L., \& Kanuk, L. (1997). Consumer behavior. New Jersey: Prentice-Hall.

Sheth, J., Mittal, B., \& Newman, B. (2001). Comportamento do cliente: indo além do comportamento do consumidor. São Paulo: Atlas.

Shimp, T. (2002). Propaganda e promoção: aspectos complementares da comunicação integrada de marketing. Porto Alegre: Bookman.

Teixeira, T. S., Wedel, M., \& Pieters, R. (2010). Moment-to-moment optimal branding in TV commercials: preventing avoidance by pulsing. Marketing Science, 29(5), 783-804. doi: $10.1287 / \mathrm{mksc} .1100 .0567$

Trindade, E. (2007). Merchandising televisivo: tie-in. In C. Perez \& I. S. Barbosa (Orgs.), Hiperpublicidade: fundamentos e interfaces (pp. 340-351). São Paulo: Thomson Learning.

Tripodi, J., Hirons, M., Bednall, D., \& Sutherlan, M. (2003). Cognitive evaluation: prompts used to measure sponsorship awareness. International Journal of Market Research, 45(4), 435-455.

Vollmers, S., \& Mizerski, R. (1994). A review and investigation into the effectiveness of product placements in films. Proceedings of the American Academy of Advertising Conference, Athens, GA, USA.

Wedel, M., \& Pieters, R. (2000). Eye fixations on advertisements and memory for brands: a model and findings. Marketing Science, 19(4), 297-312. doi: 10.1287/mksc.19.4.297.11794

Wedel, M., \& Pieters, R. (2006). Eye-tracking for visual marketing. Hanover: now Publishers.

Wedel, M., \& Pieters, R. (2008). Visual marketing: from attention to action. New York: Psychology Press.

Yi, Y. (1990). Cognitive and affective priming effects of the context for print advertisements. Journal of Advertising, 19(2), 40-48. doi: 10.1080/00913367.1990.10673186

Zanjani, S. H. A., Diamond, W. D., \& Chan, K. (2011). Does ad-context congruity help surfers and information seekers remember ads in cluttered e-magazines? Journal of Advertising, 40(4), 6784. doi: 10.2753/JOA0091-3367400405 